\title{
Effect of early maternal/newborn skin-to-skin contact after birth on the duration of third stage of labor and initiation of breastfeeding
}

\author{
Rasha Mohamed Essa ${ }_{,}^{*}$ Nemat Ismail Abdel Aziz Ismail \\ Obstetric and Gynecologic Nursing, Faculty of Nursing, Damnhour University, Damnhour, Egypt
}

Received: October 8, 2014

DOI: $10.5430 /$ jnep.v5n4p98

Accepted: January 13, $2015 \quad$ Online Published: February 2, 2015

URL: http://dx.doi.org/10.5430/jnep.v5n4p98

\begin{abstract}
The aim of this study was to determine the effect of early maternal /newborn skin-to-skin contact after birth on the duration of third stage of labor and initiation of breastfeeding. A non-randomized controlled clinical trial was conducted at a labor and delivery unit of National Medical Institution in Damanhour, Albehera Governorate, Egypt. A purposive sample of 100 laboring women was recruited. The project included a study group (50) who considered skin-to-skin contact (SSC) and a control group (50) who received routine hospital care. Three tools were used to collect data. The first tool was a structured interview to elicit socio-demographic and obstetric characteristic. Second tool was an assessment of mothers during the third stage of labor. Third tool was the Breastfeeding Assessment Tool, which comprised two parts: The Infant Breastfeeding Assessment Tool (IBFAT): and the outcome assessment of first breastfeeding. The results revealed that success in first breastfeeding was higher among study group compared to control group. There are statistically significant differences between the study and control groups in third stage of labor duration, complete placental separation, and immediate contraction of the uterus, position of uterus, absence of any abnormal signs such as uterine atony or excessive blood loss. The mean duration of the third stage of labor in the study group was significantly shorter ( $2.8 \pm 0.857$ minutes) than among those in the control group $(11.22 \pm 3.334$ minutes $)(p<.01)$. The study concluded that mothers who practice early maternal/newborn SSC immediately after birth experience shorter duration of the third stage of labor and early successful initiation of breastfeeding. Consequently, it is recommended that a continuous educational and training program be provided to all midwives and nurses working in the delivery room about the implementation of SSC for all mothers, and clarify the benefits for the mother and her neonate.
\end{abstract}

Key Words: Skin to skin contact, Infant, Mother, Third stage of labor, Success in first breastfeeding

\section{Introduction}

In many parts of the world postpartum hemorrhage and early neonatal death from inadequate feeding are significant problems. Immediate skin-to-skin contact with initiation of breastfeeding could decrease morbidity and mortality. Breastfeeding is critical for infant survival, general health, and maternal health and is a part of the millennium goals, national and international policies. World Health Organization (WHO) states that over 1.5 million baby deaths per year occur because of inadequate intake of breast milk. When we compare non-breastfed infants are at least, 2.5 times more likely to be effected by diseases than breastfedinfants. ${ }^{[1-3]}$ Breastfeeding and early initiation of Skin to Skin Contact (SSC) in the first hour after birth can lead to $22 \%$ reduction in mortality of infants in the first 28 days of

\footnotetext{
${ }^{*}$ Correspondence: Rasha Mohamed Essa; Email: rashaessa111@yahoo.com; Address: Obstetric and Gynecologic Nursing, Faculty of Nursing, Damnhour University, Damnhour, Egypt.
} 
life. Initiation of successful breast-feeding through SSC is a basic step recommended in the "Ten Steps to Successful Breastfeeding", $[4,5]$

The Baby Friendly Hospital Initiative (BFHI) states that newborn babies having immediate contact with their mothers for at least an hour after birth are more likely to continue breast feeding for a longer duration. ${ }^{[6]}$ Skin-to-skin contact is defined as the holding of the newborn baby undressed in a prone position against the mother's bare chest between breasts while the back of the baby covered with a blanket. This action is also named and known as Kangaroo Mother Care. ${ }^{[7,8]}$

The third stage of labor starts immediately after the delivery of the fetus and contains separation and expulsion of the placenta and membranes. It is the most important time for the health and wellbeing of both mother and baby, and the beginning of their special life-long relationship. ${ }^{\text {9] }}$ In most modern obstetric settings, it is now a standard practice to use drugs that cause the uterus to strongly contract to hasten the third stage, in an effort to prevent hemorrhage. This is called active management which includes early clamping of the cord, and pulling on the cord to deliver the baby's placenta quickly. In a spontaneous, unmedicated, uncomplicated birth, it is reasonable to plan a physiological or natural third stage, without increasing the risk of hemorrhage. In natural third stage, the baby's cord is usually not clamped or cut and the mother and baby stay in SSC, in a warm, nonstimulating birthing environment until after the placenta has been delivered. ${ }^{[10-12]}$

Directly after the baby has been born, the mother meets her baby for the first time and she experiences a natural behavioral pattern that supports the foundation of confident mothering, early breastfeeding, and a secure bond with her baby. Skin-to skin contact with breastfeeding involves an increase in oxytocin, endorphins and other hormones that promotes maternal child bonding. ${ }^{[13,14]}$ Maternal oxytocin levels strengthen uterine contractions that help the placenta to separate and the uterus to contract. In this way, the oxytocin prevents hemorrhage and establishes, the close bond that will ensure a mother's care and protection with the other hormones, and this helps the baby to survive. ${ }^{[15]}$

Researchers call the first 2 hours after birth, the "sensitive period", because it is the most optimal time for an infant to initiate breastfeeding. They produce actions like rooting movements, vocal cues, hand-to-mouth activity, lip smacking, etc. This period gives excellent opportunity for mothers and their babies to develop a mutual relationship when they are kept together in an intimate contact. Newborns are naturally alert and they often latch to their mother's nipple without any help. The Maximum goal of this period of successful breastfeeding can be achieved using SSC. ${ }^{[16,17]}$

Mothers and babies who experience early SSC method are more likely to have a successful breastfeeding initiation

Published by Sciedu Press and continue the process during the early postpartum period. The advantages of this method immediately following birth are many: first it makes the infant's transition to extrauterine life much easier; it improves mother's ability to care for her child; it shortens the time takes to deliver placenta; it reduces stress of mother and newborn; it has a long term positive impact on attachment behaviors. ${ }^{[18,19]}$ In addition: it regulates heartbeat, body temperature and breathing of the newborn; shortens interval between delivery, and initiation of breastfeeding; calms sleep; elongates breastfeeding period and enhances success of continued breastfeeding. ${ }^{[20,21]}$

Public agencies, NGOs, UNICEF and WHO recommend that breast feeding should begin in the first hour after giving birth and advocate it as the only feeding method for the first 6 months of life. The American Academy of Pediatrics (AAP) has recommends that "healthy infants should be placed and remain in direct SSC with their mothers immediately after delivery until the first feeding is accomplished". ${ }^{[22] ~ S k i n ~ c o n t a c t ~ i s ~ a ~ c h e a p ~ a n d ~ a ~ v e r y ~ s i m p l e ~}$ method for making post-delivery care better, increasing the duration of breastfeeding, and encouraging exclusive breastfeeding. [23]

Therefore this study aimed to determine the effect of early maternal/newborn SSC after birth on the duration of third stage of labor and initiation of breastfeeding.

The specific hypotheses to be tested are:

(1) Mothers who practice early maternal/newborn SSC after giving birth experience a short duration of the third stage of labor compared with those who do not perform this contact.

(2) Mothers who practice early maternal/newborn SSC after giving birth exhibit early successful initiation of breastfeeding compared with those who do not perform this contact.

Operational definition: In this study Skin-to-skin contact (SSC): means holding the newborn baby undressed in a prone position against the mother's bare chest between breasts while the back of the baby covered with a blanket. This skin to skin contact commences immediately after giving birth and continued for 2 hours.

\section{Design and methods}

This is a non-randomized controlled study to evaluate the effect of skin-to-skin contact immediately post delivery on the duration of the third stage of labor and initiation of breastfeeding. Both manipulation and control were utilized in the research design, while randomization was not followed in the sampling technique.

The study was conducted at the labor and delivery unit of National Medical Institution in Damanhour, Albehera Governorate. Subjects were selected through a non-randomized 
purposive sample of 100 laboring women. Each laboring woman meeting the following conditions were included in the study:

- Primigravida.

- Normal pregnancy.

- Full-term (38 to 42 weeks of gestation).

- Single viable fetus in cephalic presentation.

- Anticipated normal vaginal delivery and desire to breast-feed the baby at birth.

- Did not receive any pharmacological pain relief substance.

- Willing to join the study.

The selected parturients were purposefully assigned to groups. The first 50 subjects became the control group, then the next 50 were included in the study group. This was done to avoid sample contamination.

The control group comprised 50 parturients who received the routine hospital care. The baby was delivered from the mother, quickly dried, and APGAR score was determined immediately after cutting the umbilical cord. Then they were put under a heating device for physical assessment and vitamin $\mathrm{K}$ injection. Finally weighing, dressing and measuring the baby were done. The babies were handed to their mothers after delivery of the placenta and repairing mother's perineal tears or episiotomy, wrapped in a blanket and the mothers were encouraged to begin breastfeeding.

The study group comprised 50 parturients who were encouraged to provide early maternal/newborn SSC after giving birth. Their babies were placed undressed in a prone position against the mother's bare chest between breasts immediately after birth, before placental delivery and suturing of tears or episiotomy, as episiotomy is done routinely to all women in both groups. The APGAR score was determined, and the baby was suctioned while on the mother's chest, well dried and covered with a pre-warmed blanket over both mother and baby the baby's head was covered with a dry cap that was replaced when it became damp to prevent heat loss. Ideally, all other interventions were delayed until the end of the first 2 hours post-birth.

Three tools were used to collect the necessary data. The tools were either developed or modified after reviewing relevant literature, and checked for content validity by a jury of 5 experts in the field. Tools reliability was managed by watching 10 cases in a pilot study, in which Kapa coefficient was 0.92 .

\section{Tool (I): Socio-demographic and obstetric structured interview schedule}

It was developed by the researchers and includes two parts. Part 1: Socio-demographic data such as age, current residence, level of education, occupation, and family income/month. Part 2: Obstetric history such as weeks of gestation, number of antenatal care, and knowledge received about breastfeeding during antenatal care. These data were collected during the first stage of labor.

\section{Tool (II): Assessment of the mother during the third stage of labor}

It included assessment of uterine contractility immediately after birth, completeness of placenta, presence of uterine atony or excessive blood loss, giving methargene, position of the uterus, duration of third stage and maternal satisfaction with the care received as well as preference for the same post-delivery care in future.

\section{Tool (III): Breastfeeding Assessment Tool}

It included two parts: Part 1: The Infant Breastfeeding Assessment Tool (IBFAT): ${ }^{\text {24] }}$ The IBFAT appraises four parameters of infant suckling competence including readiness to feed, rooting reflex, fixing (Latch on), and suckling pattern. The range of scores for each of the four components is ranged between 0-3 for a maximum total score of 12 . A final score of 10 or higher from IBFAT tool is associated with successful first feeding. Scores less than 10 represented difficulty in first breast-feeding and for this study was considered as failure. Part 2: Outcome assessment of first breastfeeding: Including assessment of the time in minutes between delivery and first breastfeeding, duration (minutes) of first breastfeeding, did the newborn attach to the nipple without help, did the newborn end the first breastfeeding by him/herself. Estimating a newborn's first breastfeeding experience and success of subsequent breastfeeds before discharge will be based on the IBFAT tool.

The researchers, stayed with each woman until the end of the first 2 hours after birth. During this time the tool (II) was used to assess the mothers during the third stage of labor in both groups. And also tool (III) was used to assess the success of the first breastfeeding. The breastfeeding process was continued until infants gave up the breast in both of the groups. The time to, and the duration of the first breastfeeding was measured and recorded, and the success of a subsequent breastfeeding before discharge was also assessed.

An official letter from the Faculty of Nursing, Damanhour University was directed to the responsible authorities to obtain their permission to conduct the study after explaining its purpose. The aim of the study was explained to each laboring women and an oral agreement for participation in the study was gained. Those who agreed to participate were assured about confidentiality, privacy and their right to leave the study at any time. A pilot study was carried out on 10 laboring women (who were excluded from the study sample) to ascertain the clarity and the applicability of the tools.

The study was conducted over a period of 4 months beginning October 2013 till the end of January 2014. Sta- 
tistical analysis was done after collection of data by using Statistical Package for Social Sciences (SPSS) version 16. Descriptive and analytical statistics were used such as percentages, means and standard deviations. Chi-square-test, Fisher Exact-test, and $T$-test with a $P$ value was set at .01 to identify statistical significance difference between the results.

\section{Results}

There were no statistically significant differences among the study and control groups in relation to their sociodemographic and obstetric history (see Table 1). Where, the mean age was $23.78 \pm 3.559$ years for study group compared to $24.04 \pm 2.850$ years for of the control group. Forty-six percent of the study group had secondary level of education, compared to $52 \%$ of the control group. Twothirds $(70 \%)$ of the study group were housewives, compared to $80 \%$ of the control group. The majority of the study and control group (80\% and $74 \%$ respectively) were urban dwellers. One-half $(50 \%)$ of both groups had adequate income or more. The vast majority of the study and control group ( $88 \%$ and $86 \%$, respectively) had 4 or more antenatal visits. Both groups delivered around 39 weeks gestation. Most of the study and the control groups (98\% \& 96\%) respectively didn't receive prior information about breastfeeding.

It was observed that $100 \%$ of the study group had a contracted uterus immediately after birth, with a complete placenta, no uterine atony or excessive blood loss compared to $60 \%, 80 \%, \& 72 \%$ of the control group (see Table 2 ). These findings were statistically significant $(P<.01)$. Almost all $(98 \% \& 96 \%)$ of the study group had no need for methargene and the level of the uterus was at or below the level of umbilicus compared to only $22 \% \& 76 \%$ of the control group (see Table 2 ). These findings were statistically significant $(P<.01)$.

Table 1: Number, percent and mean distribution of study subjects according to their socio-demographic and obstetric data

\begin{tabular}{|c|c|c|c|c|c|}
\hline \multirow{2}{*}{ Socio-demographic and obstetric data } & \multicolumn{2}{|c|}{ Study Group (50) } & \multicolumn{2}{|c|}{ Control Group (50) } & \multirow{2}{*}{$\mathbf{F E T} / \chi^{2}(P)$} \\
\hline & No & $\%$ & No & $\%$ & \\
\hline \multicolumn{6}{|l|}{ Age (years): } \\
\hline $20-$ & 32 & 64.0 & 34 & 68.0 & \multirow{3}{*}{$0.426(.808)$} \\
\hline $25-$ & 16 & 32.0 & 15 & 30.0 & \\
\hline $30-35$ & 2 & 04.0 & 1 & 02.0 & \\
\hline Mean \& SD & \multicolumn{2}{|c|}{$23.78 \pm 3.559$} & \multicolumn{2}{|c|}{$24.04 \pm 2.850$} & \\
\hline \multicolumn{6}{|l|}{ Level of education: } \\
\hline Illiterate/read \& write & 7 & 14.0 & 3 & 06.0 & \multirow{4}{*}{$2.397(.494)$} \\
\hline Primary/ preparatory. & 10 & 20.0 & 13 & 26.0 & \\
\hline Secondary & 23 & 46.0 & 26 & 52.0 & \\
\hline University & 10 & 20.0 & 8 & 16.0 & \\
\hline \multicolumn{6}{|l|}{ Occupation: } \\
\hline Housewife & 35 & 70.0 & 40 & 80.0 & \multirow[t]{2}{*}{$1.333(.248)$} \\
\hline Working & 15 & 30.0 & 10 & 20.0 & \\
\hline \multicolumn{6}{|l|}{ Current residence: } \\
\hline Urban & 40 & 80.0 & 37 & 74.0 & \multirow[t]{2}{*}{$0.508(.476)$} \\
\hline Rural & 10 & 20.0 & 13 & 26.0 & \\
\hline \multicolumn{6}{|l|}{ Family income/month: } \\
\hline More than enough & 5 & 10.0 & 3 & 06.0 & \multirow{4}{*}{$0.9(.825)$} \\
\hline Enough & 25 & 50.0 & 25 & 50.0 & \\
\hline Just enough & 16 & 32.0 & 19 & 38.0 & \\
\hline Not enough & 4 & 08.0 & 3 & 06.0 & \\
\hline \multicolumn{6}{|l|}{ Number of antenatal visits: } \\
\hline$<4$ & 6 & 12.0 & 7 & 14.0 & \multirow[t]{2}{*}{$0.088(0.767)$} \\
\hline$\geq 4$ & 44 & 88.0 & 43 & 86.0 & \\
\hline \multicolumn{6}{|l|}{ Information received about breastfeeding: } \\
\hline - Yes & 1 & 02.0 & 2 & 04.0 & \multirow[t]{2}{*}{$0.344(0.558)$} \\
\hline - No & 49 & 98.0 & 48 & 96.0 & \\
\hline $\begin{array}{l}\text { Weeks of gestation: } \\
\text { Mean \& SD }\end{array}$ & \multicolumn{2}{|c|}{$39.315 \pm 0.730$} & \multicolumn{2}{|c|}{$39.455 \pm 0.679$} & $\begin{array}{l}T(P) \\
0.993(.322) \\
\end{array}$ \\
\hline
\end{tabular}

Note. $\chi^{2}(P):$ Chi-Square Test $\& P$ for $\chi^{2}$ Test; FET $(P)$ : Fisher Exact Test $\& P$ for FET-Test; $T(P): T$-test $\& P$ for $T$-test; *: Significant at $P \leq .01$ 
In relation to maternal satisfaction with the care received, it was obvious that the most $(92 \%)$ of the study group was satisfied with the care received, compared to $52 \%$ of the control one. Moreover, almost all the study group (98\%) reported that they would prefer to get the same post- delivery care in the future, compared with $66 \%$ of the control subjects. Statistically significant differences were observed between the two groups regarding their satisfaction with care and preference for same post-delivery care in future $(p<.01)$.

It was also observed from the table that the third stage duration was shorter in the study group than in control group. Where, the mean duration for the study group was $2.8 \pm$ 0.857 minutes as compared to $11.22 \pm 3.334$ minutes in the control group. The difference between the two groups here was statistically significant, $(p<.01)$. It was found that the $94 \%$ of the study group had successful first breastfeeding, compared to $56 \%$ of the control group $(p<.01)$ (see Figure 1).

The number, percent and mean distribution of both groups according to the character of the first breastfeeding is shown in Table 3. Newborn self-initiated attachment to the nipple occurred in $94 \%$ of the study group compared to only $40 \%$ of the control group $(p<.01)$. In addition, $88 \%$ of the study group's newborns ended the first breastfeeding by themselves compared to only $42 \%$ of the control one $(p<$ $.01)$. On asking the participants to estimate the newborns first breastfeeding, $90 \%$ of the study group reported good breastfeeding compared to only $40 \%$ of the control group ( $p$ $<.01)$.

The time between delivery and first breastfeeding was significantly shorter among the study group than in the control group, where the mean time was $28.66 \pm 4.6$ minutes compared to $107.72 \pm 26.5$ minutes among the study and the control groups, respectively $(p<.01)$. In addition, the duration of first breastfeeding was longer in study group than in control group, where the mean duration was $20.06 \pm 2$ minutes and $6.36 \pm 1$ minutes among the study and control groups, respectively $(p<.01)$. All of the study group and $70 \%$ of the control group were successfully breastfeeding before discharge $(p<.01)$ (see Figure 2).

Table 2: Number, percent and mean distribution of the study subjects according to their assessment of the third stage of labor

\begin{tabular}{|c|c|c|c|c|c|}
\hline \multirow{2}{*}{ Assessment of mother during third stage } & \multicolumn{2}{|c|}{ Study Group $(n=50)$} & \multicolumn{2}{|c|}{ Control Group $(n=50)$} & \multirow{2}{*}{ FET $/ \chi^{2}(P)$} \\
\hline & No & $\%$ & No & $\%$ & \\
\hline \multicolumn{6}{|l|}{ Uterus contract immediately after birth: } \\
\hline - Yes & 50 & 100.0 & 30 & 60.0 & \multirow{2}{*}{$25\left(.000^{*}\right)$} \\
\hline - No & 0 & 00.0 & 20 & 40.0 & \\
\hline \multicolumn{6}{|l|}{ Completeness of placenta: } \\
\hline - Yes & 50 & 100.0 & 40 & 80.0 & \multirow[t]{2}{*}{$11.111\left(.001^{*}\right)$} \\
\hline - No & 0 & 00.0 & 10 & 20.0 & \\
\hline \multicolumn{6}{|c|}{ Presence of uterine atony or excessive blood loss: } \\
\hline - Yes & 0 & 00.0 & 14 & 28.0 & \multirow[t]{2}{*}{$16.279\left(.000^{*}\right)$} \\
\hline - No & 50 & 100.0 & 36 & 72.0 & \\
\hline \multicolumn{6}{|l|}{ Giving methargen: } \\
\hline - Yes & 1 & 02.0 & 39 & 78.0 & \multirow{2}{*}{$60.167\left(.000^{*}\right)$} \\
\hline - No & 49 & 98.0 & 11 & 22.0 & \\
\hline \multicolumn{6}{|l|}{ Position of the uterus: } \\
\hline - At or lower than the umbilicus & 48 & 96.0 & 38 & 76.0 & \multirow[t]{2}{*}{$8.306(.004)$} \\
\hline - Highly above the umbilicus & 2 & 04.0 & 12 & 24.0 & \\
\hline \multicolumn{6}{|l|}{ Maternal satisfaction with the care received: } \\
\hline - Satisfied & 46 & 92.0 & 26 & 52.0 & \multirow{3}{*}{$24.466\left(.000^{*}\right)$} \\
\hline - Fairly satisfied & 4 & 08.0 & 15 & 30.0 & \\
\hline - Unsatisfied & 0 & 00.0 & 9 & 18.0 & \\
\hline \multicolumn{6}{|c|}{ Preference for same post-delivery care in future: } \\
\hline - Certain & 49 & 98.0 & 33 & 66.0 & \multirow{3}{*}{$17.622\left(.000^{*}\right)$} \\
\hline - Quite certain & 1 & 02.0 & 7 & 14.0 & \\
\hline - Not certain & 0 & 00.0 & 10 & 20.0 & \\
\hline \multicolumn{6}{|l|}{ Duration of third stage of labor: } \\
\hline Less than 5 minute. & 48 & 96.0 & 2 & 04.0 & \multirow{3}{*}{$84.913\left(.000^{*}\right)$} \\
\hline $5-$ & 2 & 04.0 & 25 & 50.0 & \\
\hline $10-15$ & 0 & 00.0 & 23 & 46.0 & \\
\hline Mean \& SD & $2.8=$ & & 11.2 & & $\begin{array}{l}T(P) \\
17.296\left(000^{*}\right)\end{array}$ \\
\hline
\end{tabular}

Note. $\chi^{2}(P)$ : Chi-Square Test $\& P$ for $\chi^{2}$ Test; FET $(P)$ : Fisher Exact Test $\& P$ for FET-Test; $T(P): T$-test $\& P$ for $T$-test; *: Significant at $P \leq .01$ 


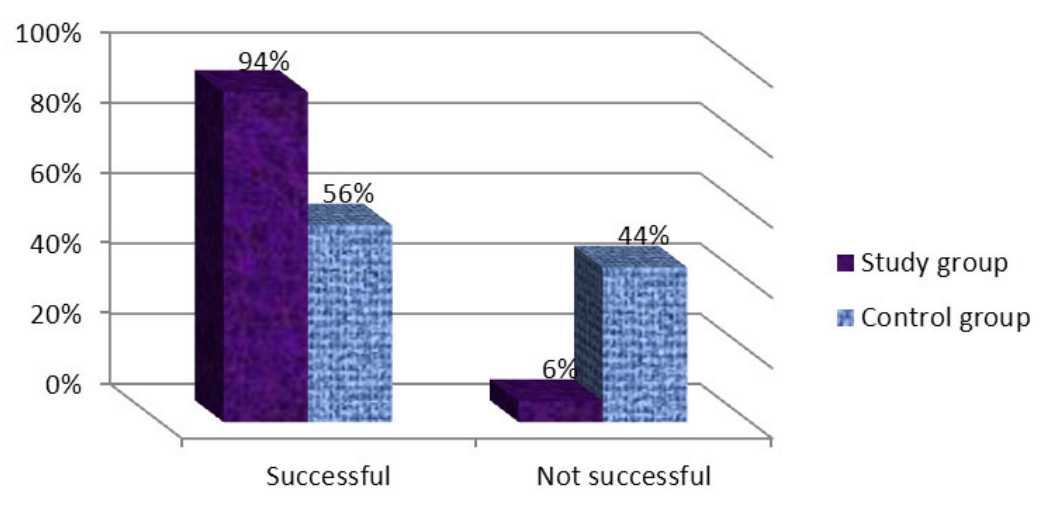

Total score of successful breast feeding

Figure 1: Percent distribution of the study subjects according to their total score of successful first breastfeeding based on IBFAT scores

Table 3: Number, percent and mean distribution of the study subjects according to their assessment of the first Breastfeeding

\begin{tabular}{|c|c|c|c|c|c|}
\hline \multirow{2}{*}{ Assessment of the first Breastfeeding } & \multicolumn{2}{|c|}{ Study Group $(n=50)$} & \multicolumn{2}{|c|}{ Control Group $(n=50)$} & \multirow{2}{*}{ FET $/ \chi^{2}(P)$} \\
\hline & No & $\%$ & No & $\%$ & \\
\hline \multicolumn{6}{|c|}{ The newborn attach to the nipple by him/herself: } \\
\hline - Yes & 47 & 94.0 & 20 & 40.0 & \multirow{2}{*}{$32.972(.000 *)$} \\
\hline - No & 3 & 06.0 & 30 & 60.0 & \\
\hline \multicolumn{5}{|l|}{$\begin{array}{l}\text { The newborn end the first breastfeeding by } \\
\text { him/herself: }\end{array}$} & \multirow{3}{*}{$23.253(.000 *)$} \\
\hline - Yes & 44 & 88.0 & 21 & 42.0 & \\
\hline - No & 6 & 12.0 & 29 & 58.0 & \\
\hline \multicolumn{6}{|l|}{$\begin{array}{l}\text { How do you estimate the newborn's first } \\
\text { breastfeeding? }\end{array}$} \\
\hline - Good & 45 & 90.0 & 20 & 40.0 & \multirow[t]{3}{*}{$27.815\left(.000^{*}\right)$} \\
\hline -Fairly good & 3 & 06.0 & 12 & 24.0 & \\
\hline -Bad & 2 & 04.0 & 18 & 36.0 & \\
\hline $\begin{array}{l}\text { Time (minutes) between delivery and first } \\
\text { breastfeeding: }\end{array}$ & \multicolumn{2}{|c|}{$33.76 \pm 3.280$} & \multicolumn{2}{|c|}{$107.72 \pm 26.511$} & $19.577\left(.000^{*}\right)$ \\
\hline Duration (minutes) of first breastfeeding: & \multicolumn{2}{|c|}{$20.06 \pm 2.084$} & \multicolumn{2}{|c|}{$6.36 \pm 1.306$} & $39.389(.000 *)$ \\
\hline
\end{tabular}

Note. $\chi^{2}(P)$ : Chi-Square Test $\& P$ for $\chi^{2}$ Test; FET $(P)$ : Fisher Exact Test $\& P$ for FET-Test; $T(P): T$-test $\& P$ for $T$-test; $*$ : Significant at $P \leq .01$

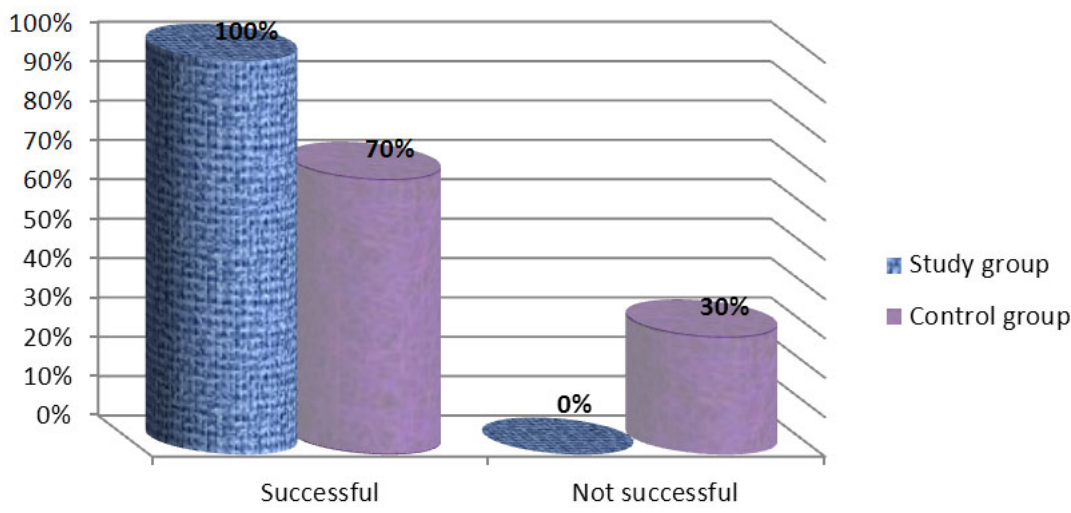

Success of subsequent breastfeeding before discharge

Figure 2: Percent distribution of study subjects according to their success of subsequent breastfeeding before discharge based on IBFAT scores 


\section{Discussion}

The early contact between the mother and the baby gives the mother immediate access to their newborn, allows them to feel closer to their babies and helps them initiate successful breast feeding. ${ }^{[25]}$ Accordance to the WHO (1996), this early contact is most beneficial and should be encouraged in situations of low risk and normal childbirth. ${ }^{[26]}$ It prevents hypothermia in infants, enhances maternal-infant interaction, and helps stimulate the delivery of the placenta as well as provides lower risk breast cancer as result of breastfeeding. The action of oxytocin and the movements of the newborn feet pressing on the uterus, leads to a decreased risk of postpartum hemorrhage. ${ }^{[27,28]}$ The early contact is a cost-effective process to improve the quality of care, and is one of the basic steps in achieving Millennium Development Goals 4 and 5 of lowering the mortality of the child and improvement of maternal health. ${ }^{[29]}$

The present study results revealed a statistically positive effect of SSC in relation to many factors during the third stage of labor that include complete placental separation, immediate uterine contraction after birth, uterus position between umbilicus and pubic bone, absent of any abnormal signs of uterine atony or postpartum hemorrhage and requiring methargene to cause uterine contraction. Similar findings have been reported in an earlier study carried out in Baghdad, Iraq, by Mejbel and Ali (2012) on the effectiveness of Skin-to-Skin contact on the duration of third stage of labor. $^{[30]}$ In addition, these results are in accordance with the findings of Joshi trial (2012). She studied the impact of child birth kangaroo care on maternal and neonatal outcomes. She found that Birth Kangaroo Care (BKC) improves the outcome for the mother in terms of height of uterus, hardness of uterus, and pain after BKC. ${ }^{[31]}$

In this respect, the present study revealed that the average duration of the third stage of labor among the study group was approximately 9 minutes shorter in the study group. This finding is likely attributed to the maternal /newborn contact and the baby's first attempts to nurse stimulating the release of maternal oxytocin, and strengthen the uterine contractions that help detach placenta, reducing the height of the uterus, and decreasing blood loss. ${ }^{[32,33]}$ Similar finding was reported by Mejbel and Ali (2012) who have elaborated a significant decrease in placental separation time between the study and control groups using SSC. ${ }^{[30]}$

In addition, this present study finding is also in line with the findings of Gabriel et al. (2010) ${ }^{[34]}$ and Dordevic I (2008). ${ }^{[35]}$ The first had studied the effects of early skinto-skin contact on the mother and the newborn. They had reported that time to expulsion of the placenta was shorter in mothers of SSC infants than in control mother. The second had investigated the benefit of an early contact with the baby for the mother. They attributed their results to the fact that when the newborn touches her mother's abdomen, the knees and legs press into her abdomen in a massage that stimulates uterine contractions and therefore decreases the risk of postpartum hemorrhage.

In spite of concern and views of some hospital staff that mothers may refuse skin-to-skin contact with their infant within the first 2 hours after birth. The present study revealed that an early and persistent skin-to-skin contact among the mother and the infant during the third stage of labor and two hours after was associated with a high level of maternal satisfaction with care received in the study group compared with conventional care of the infant practiced in many delivery rooms around the world. Many studies to date have found that women satisfied with skin-to-skin contact when it is offered. ${ }^{[36-40]}$

It is interesting to note in the present study that almost all the study group (98\%) reported that they would prefer to have the same post-delivery care in the future as compared with $66 \%$ of the control group. Again these data are representative to the larger pool of data from other researchers. ${ }^{[36,37,41]}$

The result of the present study showed that, the contact through the skin between woman and her newborn was associated with greater success at the first breastfeeding according to the scores achieved from IBFAT scale, which reflects the preparation of the infant to begin breastfeeding and their performance in sucking the breast, was better in study group than control one. This finding may be attributed to the fact that there is increased tactile and verbal stimulation from the mothers to their newborn babies through skin contact.

It is not totally clear why SSC improves breastfeeding behaviors of healthy full term infants but similar finding have been reported in the literature. ${ }^{[39]}$ A study carried out in USA by Moore and Anderson (2007), ${ }^{[42]}$ the second was carried out in Iran by Khadivzadeh and Karimi (2009), [43] and the third was carried out in Pakistan by Mahmood et al. $(2011)^{[38]}$ all showed that this early contact improved breastfeeding initiation and prolonged the duration of breastfeeding in infants. Moreover, the American College of NurseMidwives (2013) stated that with SSC the baby will smell and find the nipple so that breastfeeding is initiated by the infant more rapidly and successfully. ${ }^{[4]}$

On the other hand, a study by Carfoot et al. (2003) ${ }^{[36]}$ in the north of England revealed that the success of the first breastfeeding rate was not statistically different between the SSC group and controls. This could be due to a difference in scoring of success between this study and the Carfoot study. They used the IBFAT scores from 8 to 12 as a successful first breastfeeding experience. While in the present study, the achievement of success was measured with scores ranging from 10 to 12 . Any score lower than 10 was considered unsuccessful.

The current finding of increased latching on is consistent with the study of Svensson et al. (2013) in Stockholm, Swe- 
den, which concluded that to reduce future problems with latching on a healthy neonate needs to remain in skin contact with the mother directly following delivery, and continuously during the post partum residence. This will ensure that the infant will be capable of breastfeeding when breastfeeding reflexes are well developed. ${ }^{[46]}$

The current study result showed that, the average time for initiating the first breastfeeding after childbirth was approximately 29 minutes in intervention group while, this time was nearly two hours in the routine care group. Moreover, the first breast feeding duration in the SSC group was 20 minutes-3 times more often than the control one (6.36 minutes). Khadivzadeh and Karimi (2009) ${ }^{[43]}$ concluded that early and continues SSC in the first two hours after giving birth eases the first time of successful breastfeeding that then improves breastfeeding successful in the future. So, immediate SSC between the mother and her baby and continuing it during repair of mother's episiotomy, is highly recommended. If it is possible, usual cares of babies should be done after finishing the first successful breastfeeding. Similarly, Mahmood et al. (2011) ${ }^{[38]}$ and Moore et al. (2012) ${ }^{[41]}$ stated that the time to initiate first feed was shorter in intervention group than in conventional care group thus increasing the likelihood of future success.

When the time to the first breastfeeding was delayed and equal between study and control groups as described by Moore and Anderson (2007) ${ }^{[42]}$ this success did not occur. The difference between the present study and the study of Moore and Anderson may be related to the fact that in their trial, newborns with conventional care were given to the mothers as soon as possible after delivery and the mothers were prompted to breastfeed. This was no real difference between the timing of initiation of breastfeeding in the study and control groups. Whereas in the current study, the first contact between the mother and the infant as well as first breastfeeding are delayed until the routine care of the neonate was finished. As a routine in this facility. Newborns are generally handed over to relatives when repairing the mother's episiotomy before breastfeeding is offered.

On assessing the success of subsequent breastfeeding before discharge based on IBFAT scores, it was found that the entire SSC group had successful subsequent breastfeeding before discharge, compared to $70 \%$ of the control group. Similarly, Redshaw et al. (2014) stated that early contact appeared beneficial. Women who held their infant within five minutes of birth were more likely to initiate breastfeeding and to be breastfeeding at facility discharge. ${ }^{[46]}$
Dissimilar to this finding, the study of Carfoot et al. $(2005)^{[36]}$ revealed that no significant difference in the success of subsequent breastfeeding before discharge was found between both groups. Explanation by Carfoot for this finding was the existence of a research assistant in the delivery room. This may have prompted the midwife to offer extra help to the mothers in both groups equally. This study also measured breastfeeding success differently from the current study.

\section{Conclusion}

According to the results yielded by the present study, mothers who practice early maternal/newborn skin-to-skin contact after birth experience shorter duration of the third stage of labor and exhibit early successful initiation of breastfeeding than those who do not perform skin-to-skin contact.

\section{Recommendation}

Based on these findings it is hard to rationalize not incorporating SSC into the routine immediate post-delivery care in labor and delivery units. Skin-to-skin contact between mothers and babies must be continued during the repair of perineum post delivery. If possible, routine infant's care should be delayed until the success of the first breastfeeding process. It also, must be considered that findings of present research can be generalized only to healthy mothers and neonates. However SSC has been used in preterm nurseries in the form of Kangaroo Care for many years.

In order to accomplish this goal the old paradigms of labor and delivery care need to be changed. Continuous educational and training program for all midwives in delivery rooms as well as the other nurses and assistants about the implementation of SSC method for all mothers is critical. SSC between the mother and the baby should be performed directly after delivery and continued for at least 2 hours whenever possible. These changes directly support the millennium goals for improved maternal and child health.

\section{Acknowledgements}

We thank all the women who participated in the study, all who have directly or indirectly helped us to complete this study and their support in each major step of the study.

\section{Conflicts of Interest Disclosure}

The authors declare that there is no conflict of interest statement.

\section{References}

[1] Lawrence A, Lawrence M. Breastfeeding a guide for the medical profession. 6th ed. Piladelphia: Elsevier Mosby; 2005.
[2] WHO, UNICEF, CDD. Participant's manual, part three, Sessions 1-9. Available from: http://www. who.int/child_adolescent _health/documents/pdfs/bc_participants_manual.pdf. Lastaccessedon: 5August2013.

[3] Long S. Breastfeeding special care babies. 2nd ed. Edinburgh: Bail- 
liere tindall; 2002.

[4] Baby-Friendly USA. The ten steps to successful breastfeeding final report. Massachusetts. 2003. Available from: http://www.pdffinder.com/The-Ten-Steps-to-Success ful-Breastfeeding.html.

[5] Holmberg K, Peterson U, Oscarsson M. A two-decade perspective on mothers' experiences and feelings related to breastfeeding initiation in Sweden. Sexual \& Reproductive Healthcare. 2014; 4(1): $1-6$.

[6] WHO. UNICEF: Baby-Friendly Hospital Initiative, Revised Updated and Expanded for Integrated Care. Geneva: WHO Press, World Health Organization; 2009.

[7] Venancio S, Almeida H. Kangaroo Mother Care: scientific evidences and impact on breastfeeding. Jornal de Pediatria. 2004; 80(5): S173-S178. http://dx.doi.org/10.1590/S0021-755 72004000700009

[8] Moore E, Anderson G, Bergman N. Early skin to- Skin contact for mothers and their healthy newborn infants. Cochrane Database of Systematic Reviews. 2007; 3.

[9] Begley C, Gyte G, Murphy D. Active versus expectant management for women in the third stage of labor. Cochrane Database of Systematic Reviews. 2011; 11. Chichester: John Wiley and Sons.

[10] Buckley SJ. Leaving Well Alone- perspectives on a natural third stage. Gentle Birth, Gentle Mothering: The wisdom and science of gentle choices in pregnancy. J birth and Parenting. Brisbane, Australia: One Moon Press. 2005; 184-233. PMid:16274904

[11] Burke C. Active versus Expectant Management of the Third Stage of Labor and Implementation of a Protocol. J Perinat Neonat Nurs. 2010; 24(3): 215-228. PMid:20697238 http://dx. doi.org/10. $1097 /$ JPN . Ob013e3181e8ce90

[12] Evidence Based Guidelines for Midwifery-Led Care in Labor; third stage of labor. The Royal College of Midwives. 2012.

[13] WHO/UNICEF, Baby-friendly Hospital initiative: revised, updated, and expanded for integrated care. Section 2: strengthening and sustaining the Baby friendly Hospital Initiative: A course for decision makers. Geneva, World Health Organization, 2009.

[14] Phillips R. The Sacred Hour: Uninterrupted Skin-to-Skin Contact Immediately After Birth. Newborn \& Infant Nursing Reviews. 2013; 13: 67-72. http://dx.doi.org/10.1053/j.nainr.201 3. 04.001

[15] Kiss A, Mikkelsen J. Oxytocin - anatomy and functional assignments: a minireview. Endocr Regul. 2005; 39: 97-105. PMid:16468232

[16] Thukral A, Sankar M, Agarwal R, et al. Early Skin-to-Skin Contact and Breast-Feeding Behavior in Term Neonates: A Randomized Controlled Trial. Neonatology. 2012; 102: 114-119. PMid:22699241 http://dx.doi.org/10.1159/000337839

[17] Haroon S, Das J, Salam R, et al. Breastfeeding promotion interventions and breastfeeding practices: a systematic review. BMC Public Health. 2013; 13(3): 1-18.

[18] Vakilian K. The impact of mother-newborn skin-to-skin contact immediately after birth on emotional behaviors of mother before discharge and one month after labor. Rah-Avard-Danesh. 2002; 5(1): 33-36. In Persian.

[19] Cantrill R, Creedy D, Cooke M, et al. Effective suckling in relation to naked maternal-infant body contact in the first hour of life: an observation study. BMC Pregnancy and Childbirth. 2014; 14(20): $1-13$.

[20] Walters M, Boggs K, Ludington-How S, et al. Kangaroo Care at birth for full-term infants: a pilot study. MCN Am J Matern Child Nurs. 2007; 32: 375-381. PMid:17968221 http://dx.doi.org/1 0.1097/01. NMC.0000298134.39785.6c

[21] Ludington-Hoe S, Morgan K. Infant Assessment and Reduction of Sudden Unexpected Postnatal Collapse Risk During Skin-to-Skin Contact. Newborn \& Infant Nursing Reviews. 2014; 14: 28-33. http://dx.doi.org/10.1053/j.nainr.2013.12.009

[22] Gartner L, Morton J, Lawrence R, et al. American Academy of Pediatrics policy statement): Breastfeeding and the use of human milk. Pediatrics. 2005; 115: 496-506. PMid:15687461 http://dx.doi .org/10.1542/peds. 2004-2491
[23] Mikiel-Kostyra K, Mazur J, Bołtruszko I. Effect of early skin-toskin contact after delivery on duration of breastfeeding: a prospective cohort study. Acta Paediatr. 2002; 91(12): 1301-6. http: //dx.doi.org/10.1111/j.1651-2227.2002.tb02824.x

[24] Mathews MK. Developing an instrument to assess infant breastfeeding behavior in the early neonatal period. Midwifery. 1988; 4: 15465. http://dx.doi.org/10.1016/S0266-6138(88)80071-8

[25] Byaruhanga R, Bergstrong A, Tibemanya J, et al. Perceptions among post-delivery mothers of skin-to-skin contact and newborn baby care in a periurban hospital in Uganda. Midwifery. 2008; 24 : 183-189. PMid:17320253 http://dx.doi.org/10.1016/j.mid w. 2006.09.002

[26] World Health Organization. Care in Normal Birth: a Practical Guide. Report of a Technical Working Group. WHO, Geneva. 1996.

[27] Edmond KM, Zandoh C, Quigley MA, et al. Delayed Breastfeeding Iniciation Increases Risk of Neonatal mortality. Pediatrics. 2006; 117(3): 380-6. PMid:16510618 http://dx.doi.org/10.1542/p eds . 2005- 1496

[28] D' Artibale E, Bercini L. The practice of the fourth step of the baby friendly hospital initiative. Esc Anna Nery. 2014; 18(2): 356-364. http://dx.doi.org/10.5935/1414-8145.20140052

[29] Monteiro J, Gomes F, Nakano A, et al. Women's feelings about early contact with their infants on the labor ward. Midwifery. 2011; 27: 484-488. PMid:20451310 http://dx.doi.org/10.1016/j.mid w. 2010.03 .007

[30] Mejbel M, Ali R. Effectiveness of Skin- to Skin Contact on duration of third stage of labor in Baghdad Teaching Hospital: Comparative Study. Kufa Journal for Nursing Sciences. 2012; 2(3): 1-13.

[31] Joshi S. The effect of birth kangaroo care on maternal and neonatal outcome: A randomized, controlled trial. Sinhgad e Journal of Nursing. 2012; 2(2): 13- 17.

[32] Matthiesen AS, Ransjo-Arvidson AB, Nissen E, et al. Postpartum maternal release by newborns: effects of infant hand massage and sucking. Birth. 2001: 28: 13-19. PMid:11264623 http://dx.doi . org/10.1046/j.1523-536x.2001.00013.x

[33] Bramson L, Moore E, Montgomery S, et al. Effect of Early Skinto-Skin Mother-Infant Contact During the First 3 Hours Following Birth on Exclusive Breastfeeding During the Maternity Hospital Stay. Journal of Human Lactation. 2010; 26(2):130-7.

[34] Gabriel M, Martín I, Escobar A, et al. Randomized controlled trial of early skin-to-skin contact: effects on the mother and the newborn. Acta Pædiatrica. 2010; 99: 1630-1634. PMid:19912138 http://dx.doi.org/10.1111/j.1651-2227.2009.01597.x

[35] Dordevic G, Jovanovic B, Dordevic M. An early contact with the baby - benefit for the mother. Medicina Preglio. 2008; 61(11-12): 576-9. PMid:19368275 http://dx.doi .org/10.2298/MPNS081 2576D

[36] Carfoot S, Williamson P, Dickson R. A randomized controlled trial in the north of England examining the effects of skin-to-skin care on breast feeding. Midwifery. 2005; 21(1): 71-9. PMid:15740818 http://dx.doi.org/10.1016/j.midw.2004.09.002

[37] Nahidi F, Dorri F, Ravari M, et al. Effect of early skin to skin contact of mother and newborn on mother's satisfaction. Journal of Nursing and Midwifery. 2010; 20(71): 1-5.

[38] Mahmood I, Jamal M, Khan N. Effect of mother-infant early skin-toskin contact on breastfeeding status: a randomized controlled trial. Journal of the College of Physicians and Surgeons-Pakistan: JCPSP. 2011; 21(10): 601-5. PMid:22015120

[39] Aghdas K, Talat K, Sepideh B. Effect of immediate and continuous mother-infant skin-to-skin contact on breastfeeding self-efficacy of primiparous women: A randomized control trial. Women and Birth. 2014; 27: 37-40. PMid:24216342 http://dx.doi.org/10.1016 /j.wombi.2013.09.004

[40] Srivastava S, Gupta A, Bhatnagar A, et al. Effect of very early skin to skin contact on success at breastfeeding and preventing early hypothermia in neonates. Indian Journal of Public Health. 2014; 58(1): 22-6. PMid:24748353 http://dx.doi.org/10.4103/0 019-557X. 128160

[41] Moore ER, Anderson G, Bergman N, et al. Early skin-to-skin contact for mothers and their healthy newborn infants (Review). The 
Cochrane Collaboration. Published by JohnWiley \& Sons, Ltd. 2012; 5 .

[42] Moore E, Anderson G. Randomized controlled trial of very early mother-infant skin-to-skin contact and breastfeeding status. J Midwifery Women's Health. 2007; 52(2): 116-25. PMid:17336817 http://dx.doi.org/10.1016/j.jmwh.2006.12.002

[43] Khadivzadeh T, Karimi A. The effects of post-birth mother-infant skin to skin contact on first breastfeeding. IJNMR. 2009; 14(3): 111116.

[44] American College of Nurse-Midwives. Promoting Skin-to-Skin Contact. Journal of Midwifery \& Women's Health. 2013; 58(3):
359-360. PMid:23631568 http://dx.doi.org/10.1111/jmwh. 12034

[45] Svensson K, Velandia M, Matthiesen A, et al. Effects of motherinfant skin-to-skin contact on severe latch-on problems in older infants: a randomized trial. International Breastfeeding Journal. 2013; 8(1): 1-13. PMid:23497501 http://dx.doi.org/10.1186/174 6-4358-8-1

[46] Redshaw M, Hennegan J, Kruske S. Holding the baby: Early mother-infant contact after childbirth and outcomes. Midwifery. 2014; 30: e177-e187. PMid:24680108 http://dx.doi.org/10. 1016/j.midw.2014.02.003 